\title{
Bayesian estimation of the time-varing rate and irregularity of neuronal firing
} Takeaki Shimokawa* and Shigeru Shinomoto

\author{
Address: Department of Physics, Kyoto University, Sakyo-ku, Kyoto 606-8502, Japan \\ Email: Takeaki Shimokawa* - shimokawa@ton.scphys.kyoto-u.ac.jp \\ * Corresponding author
}

from Eighteenth Annual Computational Neuroscience Meeting: CNS*2009

Berlin, Germany. 18-23 July 2009

Published: 13 July 2009

BMC Neuroscience 2009, I0(Suppl I):O6 doi:I0.I I86/I47I-2202-I0-SI-O6

This abstract is available from: http://www.biomedcentral.com/I47I-2202/I0/SI/O6

(c) 2009 Shimokawa and Shinomoto; licensee BioMed Central Ltd.

\section{Introduction}

Spike trains generated by cortical neurons possess specific characteristics such as firing irregularity (see Figure 1A) other than the firing rate. Recently, our study revealed that the firing irregularity is rather specific to individual neurons and invariant with the time and the modulation of firing rate by using a metric for analyzing the time-local irregularity of spike events $[1,2]$. On the other hand, it was also reported that the firing irregularity varied significantly according to behavioral contexts in some other cortical area [3]. Therefore, we wish to examine how easily the firing irregularity is varied with the firing rate more systematically. For this purpose, we developed a Bayesian estimation method that allows us to estimate both the instantaneous rate and irregularity for a given spike sequence [4]. In our new framework, we first consider the stochastic process of generating spikes under a given rate and irregularity, and then invert the conditional probability distribution to infer the rate and the irregularity from the data.

We applied our new method to the experimentally recorded spike data taken from Neural Signal Archive [5] (see Figure 1B), and revealed that there is a systematic correlation between firing rate and firing irregularity, and that the degree of the variability in the firing irregularity greatly depends on the cortical areas.

\section{Acknowledgements}

This study was supported in part by Grants-in-Aid for Scientific Research to SS from the MEXT Japan. TS is supported by the Research Fellowship of the JSPS for Young Scientists.

\section{References}

I. Shinomoto S, Shima K, Tanji J: Differences in spiking patterns among cortical neurons. Neural Comput 2003, 1 5:2823-2842.

2. Shinomoto S, Miyazaki Y, Tamura H, Fujita I: Regional and laminar differences in in vivo firing patterns of primate cortical neurons. J Neurophysiol 2005, 94:567-575.

3. Davies RM, Gerstein GL, Baker SN: Measurement of timedependent changes in the irregularity of neural spiking. J Neurophysiol 2006, 96:906-918.

4. Shimokawa T, Shinomoto S: Estimating instantaneous irregularity of neuronal firing. Neural Comput 2009 in press.

5. Neural Signal Archive [http://www.neuralsignal.org] 
A

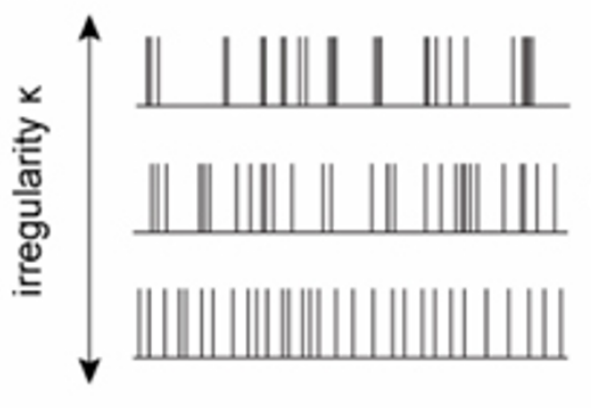

B

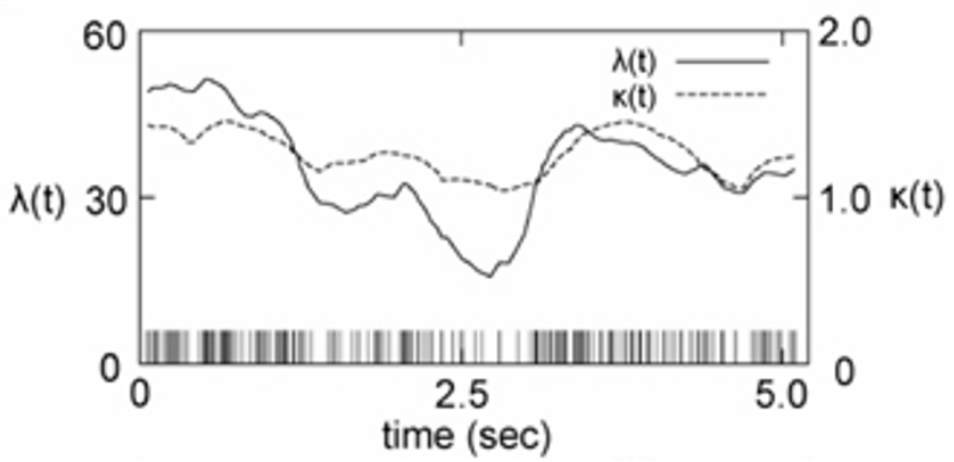

Figure I

(A) Sample sequences of events with identical rate and different irregularity, which may be termed bursty, random (Poisson), or regular. (B) The MAP estimate of the instantaneous rate $\lambda(t)$ and irregularity $\kappa(t)$ for the spike sequence $\left\{\mathrm{t}_{\mathrm{i}}\right\}$ recorded from a VI neuron of a Macaque (nsa2004.4; Neural Signal Archive [5]).

Publish with Biomed Central and every scientist can read your work free of charge

"BioMed Central will be the most significant development for disseminating the results of biomedical research in our lifetime. "

Sir Paul Nurse, Cancer Research UK

Your research papers will be:

- available free of charge to the entire biomedical community

- peer reviewed and published immediately upon acceptance

- cited in PubMed and archived on PubMed Central

- yours - you keep the copyright 